\title{
Ascites in 2nd Trimester Pregnant
}

\section{Rawa Al-Ameri*}

Family Medicine Specialist, Al-Mustansiriyah University, Iraq

*Corresponding author: Rawa Al-Ameri, Family Medicine Specialist, AlMustansiriyah University, Iraq, Email: dr_rj1983@yahoo.com

\section{Case Report}

Volume 1 Issue 1

Received Date: November 13, 2018

Published Date: November 23, 2018

DOI: $10.23880 /$ jqhe- 16000103

\section{Abstract}

Ascites is a collection of fluid in peritoneal cavity. Abdominal distention, weight gain, shortness of breath, nausea and vomiting are most common presentation. The most common causes of ascites are Disorders related to portal hypertension as liver diseases such as cirrhosis, alcoholic hepatitis and congestive heart failure, constrictive pericarditis. A 34 year female, G3P2A0, 17 week pregnant presented to Antenatal Care Clinic for regular checkup, complaining of rapid weight gain, generalized swelling, particularly; abdominal swelling and dyspnea attacks. The patient had history of hypothyroidism on thyroxin treatment, preeclampsia in previous pregnancy. By exam, the patient seemed to be fatigued with generalized edema, lower limb edema, abdominal over distention with normal fundus size and difficult to palpate fetal parts. Ultrasound show free fluid in peritoneal cavity suggesting ascites.

Keywords: Ascites; Hypoalbuminemia; Glomerular Filtration

\section{Introduction}

Ascites is a collection of fluid in peritoneal cavity. Abdominal distention, weight gain, shortness of breath, nausea and vomiting are most common presentation [1]. The most common causes of ascites are Disorders related to portal hypertension as liver diseases such as cirrhosis, alcoholic hepatitis and congestive heart failure, constrictive pericarditis [2].

Other causes include those related to hypoalbuminaemia as nephritic syndrome and protein-losing enteropathy. Ascites could be associated with miscellaneous conditions as myxedema and ovarian tumors [1,2].

Albumin is an acute-phase protein, synthesized by the liver. It is responsible for transport of various substances as fatty acids and hormones, it has an anti-thrombotic effect and it is essential in the maintenance of normal plasma colloid oncotic pressure [3,4]. Hypoalbuminemia is related to increase morbidity, short-term mortality and length of hospital stay and to more complications $[5,6]$.

Nephrotic syndrome is a condition that causes the kidneys to leak large amounts of protein into the urine, more than $3.5 \mathrm{~g} / 24 \mathrm{hr}$ with hypoalbuminemia less than 30 $\mathrm{g} / \mathrm{L}$; this can lead to a range of problems, including swelling of body tissues and increase the risk for infections. Hyperlipidemia and thrombotic disease could be seen, too $[7,8]$. So the patient may experience weight gain, edema of the legs, feet, ankles and less often in the hands or face, fatigue, foamy urine, loss of appetite $[2,7,8]$.

Most children with nephrotic syndrome could have remission period followed by relapses periods. Usually, 


\section{Journal of Quality in Health Care \& Economics}

relapses become less frequent as they get older and could be a disease free in late teens [8].

Nephrotic syndrome could lead to urinary loss of hormone-binding proteins. So, significant increase in urinary excretion of T3 (triiodothyronine), (tetraiodothyronine) T4 and (thyroid-binding globulin) TBG could lead to emerge of clinical hypothyroidism $[2,8,9]$. Since proteins in human body can be affected by various ways as it is mentioned in a case report by RJK AlAmeri [10].

\section{Case Presentation}

A 34 year female, G3P2A0, 17 week pregnant presented to Antenatal Care Clinic for regular checkup, complaining of rapid weight gain, generalized swelling, particularly; abdominal swelling and dyspnea attacks. The patient had history of hypothyroidism on thyroxin treatment, preeclampsia in previous pregnancy. By exam, the patient seemed to be fatigued with generalized edema, lower limb edema, abdominal over distention with normal fundus size and difficult to palpate fetal parts. Ultrasound show free fluid in peritoneal cavity suggesting ascites (Figure 1).

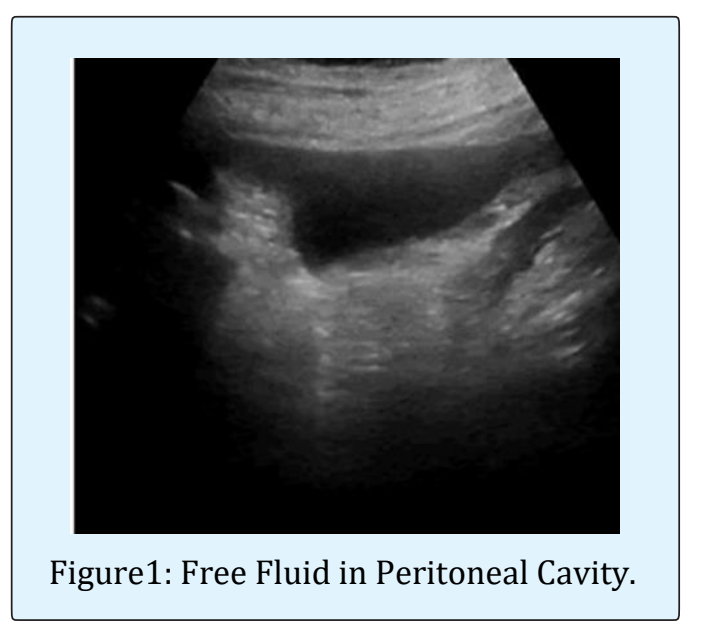

The patient is on a large dose of thyroxin, 250 microgram; to control her hypothyroidism, as she had normal T3, T4, and TSH in lab test with the current dose (Tables $1 \& 2$ ). She had normal blood urea and serum creatinine with slight decrease in glomerular filtration rate; $68 \mathrm{mg} / \mathrm{m} \mathrm{mol}$, normal complete blood count and normal liver enzymes with marked decrease in serum albumin; $1.1 \mathrm{~g} / \mathrm{dl}$, massive albuminuria in urine test and marked hyperlipidemia in lipid profile. Blood pressure is $110 / 65$.

\begin{tabular}{|c|c|c|}
\hline Test name & Result & Normal values \\
\hline Color & Yellow & \\
\hline Aspect & Turbid & \\
\hline Volume & Voided sample & \\
\hline Reaction & 6 & $4.7-7.8$ \\
\hline Specific gravity & 1.005 & $1.005-1.025$ \\
\hline Nitrite & Nil & Not detected \\
\hline Albumin & +++ & Not detected \\
\hline Sugar & Nil & Not detected \\
\hline Aceton & Nil & Not detected \\
\hline Bile salts & Nil & Not detected \\
\hline Bile pigments & Nil & Not detected \\
\hline Urobilinogen & Normal trace & Normal trace \\
\hline RBCs & 4 -Feb & $0-1$ \\
\hline Pus cell & 6 -Apr & $0-1$ \\
\hline Epithelial cells & Few & \\
\hline Casts & Nil & \\
\hline Crystal & + urate crystal & \\
\hline Others & Nil & \\
\hline
\end{tabular}

Table 1: General Urine Exam.

\begin{tabular}{|c|c|c|}
\hline Serum & Results & Normal range \\
\hline Cholesterol & 9.9 & $5.43 \mathrm{mmol} / \mathrm{l}$ \\
\hline Ttriglyceride & 2.78 & $1.10 \mathrm{mmol} / \mathrm{l}$ \\
\hline
\end{tabular}

Table 2: Lipid Profile.

Childhood records revealed that the patient had nephrotic syndrome in early life and went through a remission period since age of six years. Obviously, the pregnancy triggered the disease once again showing a picture of adult nephrotic syndrome. With a consultation with nephrologist, prednisolone tabs is administered at a dose of $2 \mathrm{mg} / \mathrm{kg} /$ day. Normal urine and serum albumin is resumed with other lab tests. Ascites resolved gradually with improving the general condition. The required dose of Thyroxin is decreased gradually to 25 microgram per day and then the patient got a euthyroid state, so thyroxin treatment is ceased. Pregnancy continued smoothly.

\section{Discussion}

Ascites in pregnancy could be due to many conditions, the most common one is preeclampsia as it is associated with protein urea, too. This is mentioned in a case report done by Abe Golden.11 Ascites in preeclampsia is due to low serum protein with alteration in the albumin-globulin ratio; liver damage and hemoconcentration [11]. Even though, the patient in the current case had history of preeclampsia in previous pregnancy and protein urea in 


\section{Journal of Quality in Health Care \& Economics}

the recent pregnancy but the patient had normal blood pressure and normal liver enzymes that make liver disease as a possible cause of ascites is far away, too, since the patient had no signs and symptoms of liver disease, as well, even she had hypoalbuminemia that could occur in liver disease and leading also to ascites [12].

The patient had a picture of nephrotic syndrome that caused the ascites due to hypoalbuminemia but pregnancy may cause a misleading. Since the patient had proteinuria, hypoalbuminemia, hyperlipidemia and edema [7].

The patient had a nephrotic syndrome in early childhood and remission for long period is achieved but unfortunately, pregnancy induce relapse since a state of immunosuppression is associated with pregnancy that may lead to elicit medical conditions [13].

Excessive protein loss in urine in nephrotic syndrome, leading to a loss of T3 and T4 in urine, which caused a state of hypothyroidism [9]. By cortisone treatment, the patient resumed gradually the euthyroid state.

\section{Conflict of Interest}

The authors have no conflicts of interest.

\section{Ethical Approval}

Ethical approval is obtained.

\section{Consent}

Consent is obtained.

\section{References}

1. Ascites. Johns Hopkins Medicine Health Library.

2. (2018) BMJ Best Practices: Diabetic Retinopathy. BMJ Publ Group.
3. Vincent JL, Dubois MJ, Navickis RJ, Wilkes MM (2003) Hypoalbuminemia in acute illness: is there a rationale for intervention? A meta-analysis of cohort Studies and controlled trials. Ann Surg 237(3): 319-334.

4. Foley RN, Parfrey PS, Harnett JD, kent GM, Murray DC, et al. (1996) Hypoalbuminemia, Cardiac Morbidity, and Mortality in End-Stage Penal Disease 7(5): 728736.

5. Sridhar NR, Josyula S (2013) Hypoalbuminemia in hemodialyzed end stage renal disease patients: risk factors and relationships - a 2 year single center study. BMC Nephrol 14(1): 242.

6. Yu M, Lee SW, Baek SH, Ki Young Na, Chae DW, et al. (2017) Hypoalbuminemia at admission predicts the development of acute kidney injury in hospitalized patients: A retrospective cohort study. PLoS One 12(7): 1-14.

7. Nephrotic Syndrome in Adults NIDDK.

8. Adhikari M, Coovadia HM, Loening WE (1994) Nephrotic syndrome in children. Pediatriia 122(1): 514-519.

9. Park SJ, Shin JI (2011) Complications of nephrotic syndrome. Korean J Pediatr 55(4): 151.

10. Ameri R Al (2017) False Positive Rubella Test In Pregnancy. J Womens Heal Care 6(4): 1-2.

11. Golden A (1949) Ascites in pregnancy. Am J Obstet Gynecol 57(2): 385-387.

12. Gatta A, Verardo A, Bolognesi M (2012) Hypoalbuminemia. Intern Emerg Med 7(S3): S193199.

13. Mor G, Cardenas I (2010) The immune system in pregnancy: a unique complexity. Am J Reprod Immunol 63(6): 425-433. 